\title{
AMBIENTES POTENCIALIZADORES PARA INCLUSÃO: PESQUISA SOBRE INCLUSÃO, DIGITAL, ESCOLAR E SOCIAL DE PESSOAS COM DEFICIÊNCIA
}

Janiele de Souza Santos ${ }^{1}$, Denner Dias Barros ${ }^{1}$, Ana Virginia Isiano Lima ${ }^{2}$, Ana Mayra Samuel Silva ${ }^{2}$, Danielle Aparecida do Nascimento Santos ${ }^{3}$, Elisa Tomoe Moriya Schlünzen ${ }^{3}$

Universidade Estadual Paulista Júlio de Mesquita Filho - UNESP. ${ }^{1}$ Curso de Matemática, Presidente Prudente - SP. ${ }^{2}$ Curso de Pedagogia, Presidente Prudente - SP. ${ }^{3}$ Doutorado em Educação, Presidente Prudente - SP. E-mail: janiele.unesp@gmail.com

\section{RESUMO}

Desde o ano de 2002 o grupo de pesquisa Ambientes Potencializadores para Inclusão (API) vem realizando pesquisas e práticas sobre os Estudantes Público Alvo da Educação Especial (EPAEE). O objetivo principal das atividades dos pesquisadores do grupo é o desenvolvimento de estratégias para a Inclusão Digital, Escolar e Social desses estudantes. Por meio dos projetos de pesquisa e extensão com ênfase no uso de Tecnologias Digitais de Informação e Comunicação (TDIC) em um ambiente Construcionista, Contextualizado e Significativo (CCS) mediante o trabalho com projetos são realizados atendimentos pedagógicos junto aos EPAEE. Além disso, é realizada a formação inicial e continuada de professores de Presidente Prudente, da região e de todo o Brasil, por meio da Educação a Distância (EaD). Os avanços e perspectivas sobre os atendimentos realizados pelos membros do grupo é foco deste artigo, evidenciando os resultados alcançados em termos de Inclusão Digital, Escolar e Social.

Palavras-chave: Ambientes Potencializadores para Inclusão, Estudantes Público Alvo da Educação Especial Inclusão.

\section{POTENTIATING ENVIRONMENTS FOR INCLUSION: RESEARCH ON DIGITAL, SCHOOL AND SOCIAL INCLUSION OF PEOPLE WITH DISABILITIES}

\begin{abstract}
Since 2002 the research group Potentiating Environments for Inclusion (API) has conducted research and practices on the students who are the target audience of Special Education. The researchers' activities main goal is to develop strategies for Digital, Social and School Inclusion of these students. Through research and extension projects focusing on the use of Digital Information and Communication Technologies on a Constructionist, Contextualized and Meaningful and with projects, pedagogical services are provided to Special Education Students. Moreover, the initial and continuing training of teachers of Presidente Prudente and the entire Brazil through Distance Education is performed. Advances and perspectives on the pedagogical services provided by members of the group is the focus of this article, evidentiating the results achieved in Digital, Social and School Inclusion.
\end{abstract}

Keywords: Potentiating Environments for Inclusion, Special Education Students, Inclusion. 


\section{INTRODUÇÃO}

A Constituição Federal de 1988 determina como fundamentos da República a cidadania e a dignidade da pessoa humana, por meio da promoção do bem de todos, sem preconceitos de origem, raça, sexo, cor, idade e quaisquer outras formas de discriminação. Além disso, os marcos legais da Educação Especial e Inclusiva como: a Constituição Federal de 1988, o Estatuto da Criança e do Adolescente (ECA, lei no 8.069/90), a Declaração de Salamanca (1994), a Lei de Diretrizes e Bases da Educação Nacional no 9.394/96 e a Política Nacional de Educação Especial na Perspectiva da Educação Inclusiva (MEC/SEESP 2008) passaram a influenciar a organização escolar e social, garantindo o direito à igualdade e o direito de todos à educação, visando o pleno desenvolvimento da pessoa, seu preparo para o exercício da cidadania e sua qualificação para o trabalho.

Diante desses pressupostos a escola passa a ter o papel principal de promover oportunidades educacionais a todos os estudantes considerando suas potencialidades e interesses e proporcionando um ensino de qualidade para todos, sem exceções, tomando para si o papel de uma escola inclusiva.

Para Rodrigues (2000),

A educação inclusiva assume-se como respeitadora das culturas, das capacidades e das possibilidades de evolução de todos (...). A educação inclusiva aposta na escola como comunidade educativa, defende um ambiente de aprendizagem diferenciado e de qualidade para todos os alunos. É uma escola que reconhece as diferenças, trabalha com elas para o desenvolvimento e dá-lhes um sentido, uma dignidade e uma funcionalidade (...) daí que designaria a educação inclusiva como 'a comunidade que aprende com todos". (p. 51)

Porém, para o estabelecimento real de escolas inclusivas dentro dessas perspectivas, enfrentamos ainda muitos desafios, e um deles diz respeito às mudanças nas práticas de ensino tradicionais e da postura perante a diferença por parte da equipe escolar.

Segundo Mantoan (1997), a inclusão das crianças com necessidades especiais é necessária, e para que ela ocorra é imprescindível que o professor seja qualificado para trabalhar na mesma sala de aula com estudantes ditos "normais" e também com aqueles que apresentam alguma necessidade educacional especial.

A Lei de Diretrizes e Bases da Educação Nacional (LDBEN 9394/96) estabelece que os professores que atuam no atendimento especializado de estudantes com deficiências devem ter especialização adequada em nível médio e superior, e os professores que atuam no ensino regular, 
nas classes comuns, devem ser formados para a interação desses educandos com os saberes que devem ser trabalhados em cada área do conhecimento.

Diante dessas premissas, Schlünzen (2000) ao desenvolver sua tese de doutorado, afirma que para contribuir com a inclusão escolar, é necessário usar Tecnologias Digitais de Informação e Comunicação (TDIC) no processo educacional, transformando o ensino instrucionista em um ensino construcionista. Nesse sentido, surge o ambiente Construcionista, Contextualizado e Significativo (CCS), que consiste em um ambiente pedagógico onde as práticas pedagógicas sejam mediadas pelo uso de TDIC e trabalho com projetos. O ambiente é Construcionista porque as TDIC são utilizadas para a construção do conhecimento por meio do uso da tecnologia; Contextualizado porque os projetos ou atividades construídas fazem parte do contexto do estudante e Significativo porque os estudantes constroem o conhecimento de acordo com o significado atribuído aos conceitos com os quais se deparam.

A partir dessa tese, no ano de 2002 foi criado pela pesquisadora o grupo de pesquisa Ambientes Potencializadores para Inclusão (API). O grupo API conta atualmente com cerca de 40 pesquisadores, sendo professores universitários, pesquisadores da área da educação, professores da educação básica, licenciandos, mestrandos, doutorandos e graduandos da Faculdade de Ciências e Tecnologia FCT/UNESP de Presidente Prudente/SP. Esses licenciandos e graduandos realizam o acompanhamento de Estudantes Público-Alvo da Educação Especial (EPAEE) - pessoas com deficiências e transtornos globais do desenvolvimento.

O objetivo principal desses acompanhamentos é a promoção da Inclusão Digital, Escolar e Social desses estudantes. Além disso, por meio dos projetos de pesquisa e extensão vinculados ao grupo, com ênfase no uso de Tecnologias Digitais de Informação e Comunicação (TDIC) são realizados cursos de formação inicial e continuada de professores.

Neste artigo será descrita a trajetória dos acompanhamentos realizados no âmbito do API e os avanços alcançados na promoção da inclusão digital, escolar e social dos EPAEE.

\section{METODOLOGIA}

Para o desenvolvimento dos projetos do grupo API voluntários e estagiários atuam no acompanhamento de EPAEE, que frequentam semanalmente o Centro de Promoção para a Inclusão Digital, Escolar e Social (CPIDES) na FCT/Unesp. Antes de iniciar as atividades de acompanhamento todos os voluntários e estagiários realizam um estudo teórico e prático sobre deficiências (físicas, 
sensoriais, motoras e intelectuais) e sobre transtornos globais do desenvolvimento. Além disso, participam de formações para aprender a usar recursos de TDIC como Objetos Educacionais e Tecnologia Assistiva.

Esses voluntários e estagiários são discentes dos cursos de graduação da FCT/Unesp e outras instituições de ensino superior do município de Presidente Prudente e região, que tem interesse em desenvolver estudos sobre acessibilidade e estratégias pedagógicas e metodológicas com o intuito de promover a inclusão digital, escolar e social de EPAEE.

Até 2010 os acompanhamentos eram realizados em um Laboratório Didático de Informática do Departamento de Matemática e Computação da FCT/Unesp. No entanto, o laboratório não possuía condições adequadas de hardware e software para o trabalho pedagógico junto aos EPAEE. Além disso, o número de pessoas atendidas aumentava a cada ano, tornando o espaço físico pequeno. Assim, em 2011 foi construído o Centro de Promoção para Inclusão Digital, Educacional e Social (CPIDES) que conta com uma Sala de Recursos Multifuncionais (SRM), Laboratório de Informática, Biblioteca, Sala de Desenvolvimento e outros ambientes que favorecem o trabalho que os pesquisadores do grupo API realizam, não só no acompanhamento aos EPAEE, como também na elaboração de cursos, recursos e estratégias que fomentam as pesquisas geradas.

Para desenvolver as atividades de pesquisa e extensão no CPIDES existe autorização do Comitê de Ética em Pesquisa (CEP), cujo protocolo de aprovação é 106/2009.

Os atendimentos pedagógicos que são realizados no CPIDES acontecem semanalmente, com duração de uma a duas horas. Antes de iniciar os atendimentos o voluntário ou estagiário realiza uma entrevista com os responsáveis pelos estudantes, buscando conhecer o real o interesse de cada um para nortear a planificação das atividades a serem desenvolvidas durante um semestre letivo.

\section{RESULTADOS}

Após as entrevistas são agendados os atendimentos, cujas propostas são centradas no interesse de cada estudante, trabalhando na perspectiva do ambiente CCS, buscando realçar as potencialidades e não as dificuldades do estudante acompanhado. O ambiente CCS, segundo Schlünzen (2000, p. 82):

É um ambiente favorável que desperta o interesse do aluno e o motiva a explorar, a pesquisar, a descrever, a refletir, a depurar as suas ideias. [...] As informações que são significativas para o aluno podem ser transformadas em conhecimento [...] $\mathrm{O}$ 
aluno consegue descobrir a relação com tudo que está aprendendo, a partir de seus interesses individuais dentro do seu contexto.

Além disso, os acompanhamentos são realizados tanto na Sala de Recursos Multifuncionais (SRM) quanto no Laboratório de Informática. No laboratório de informática os estudantes trabalham com Objetos Educacionais (OE), softwares educativos e recursos tecnológicos acessíveis. Segundo Tarouco et al (2003), Objeto Educacional é um recurso suplementar ao processo de aprendizagem, que pode apoiar a aprendizagem, sendo que principalmente visa maximizar situações de aprendizagem onde o recurso pode ser utilizado.Grande parte dos OE utilizados durante os acompanhamentos são do projeto Rede Interativa Virtual de Educação (RIVED), que teve como objetivo incentivar a produção de recursos digitais direcionados a determinadas áreas do conhecimento, oferecendo e subsidiando ações que visavam a melhoria do ensino de Ciências e Matemática nas escolas públicas. A equipe do grupo API produziu, de 2004 a 2008, 26 (vinte e seis) Objetos de Aprendizagem (OA) por meio de uma equipe multidisciplinar, que incluía especialistas em conteúdo, pedagogos, designers instrucionais, programadores e designers de multimídia.

Já na SRM os estudantes utilizam materiais pedagógicos e recursos de Tencologia Assistiva (TA) direcionados ao Atendimento Educacional Especializado. A Tecnologia Assistiva é uma área do conhecimento de característica interdisciplinar que engloba produtos, recursos, metodologias, estratégias, práticas e serviços que devem ser usados para promover a funcionalidade da pessoa com deficiência visando sua autonomia, independência, qualidade de vida e inclusão social (CAT, 2007.c).

Observamos ao longo dos 12 anos do grupo que os acompanhamentos vêm ganhando grande proporção, tanto na inclusão de pessoas com deficiências da região de Presidente Prudente quanto na abrangência dos projetos de extensão e pesquisa. Em 2014 estão sendo executados 6 projetos de extensão e pesquisa: A utilização das Tecnologias Digitais de Informação e Comunicação para a Inclusão Social, Digital e Educacional de PD (Pró-Reitoria de Extensão); A implementação de ferramentas de acessibilidade em Objetos Educacionais (OE) para a Educação Inclusiva (Pró-Reitoria de Extensão); A Formação de Professores para o uso de Tecnologia Assistiva em uma Perspectiva de Escola Inclusiva (CNPq e Núcleo de Ensino); Programa Institucional de Bolsa de Iniciação a Docência (PIBID) e Tecnologia assistiva: estratégias, práticas, serviços e recursos de acessibilidade no processo de inclusão escolar de estudantes público-alvo da Educação Especial (Observatório da Educação OBEDUC). 
Dentre os projetos citados um total de 32 (trinta e dois) bolsistas dos cursos de graduação e 4 (quatro voluntários) realizam o atendimento de 48 (quarenta e oito) EPAEE no CPIDES. São atendidos estudantes da faixa etária de 05 a 50 anos, que possuem deficiências como Síndrome de Down, Autismo, Deficiência Intelectual, Paralisia Cerebral, Síndrome de Sotos, Síndrome do X-Frágil, Síndrome de Asperger, Síndrome do X 14, Microcefalia, Hidrocefalia e Discalculia.

Cada estudante tem um nível de escolaridade: 13 frequentam a Associação de Pais e Amigos dos Excepcionais (APAE), 20 frequentam escolas de ensino básico regular, 8 estão sendo alfabetizados e 7 realizam cursos técnicos em outras instituições de ensino.

\section{DISCUSSÃO}

Por meio dos ambientes CCS buscamos proporcionar aos EPAEE a oportunidade de romper os limites e as barreiras estabelecidas pelas deficiências, demonstrando suas capacidades, proporcionando o desenvolvimento cognitivo, afetivo e social, melhorando também sua autoestima.

Ao longo desses anos obtivemos muitas conquistas e as principais delas foram: a inserção dos EPAEE no mundo de trabalho; esclarecimento dos professores em formação e dos profissionais, em relação ao trabalho com os EPAEE utilizando como ferramenta a Tecnologia Educacional; divulgação de materiais desenvolvidos pelo grupo (congressos, periódicos da área, imprensa e ambiente acadêmico em geral) e uma das conquistas mais importantes, a inclusão dos EPAEE em salas comuns do ensino regular.

Nesse sentido, realizamos o desenvolvimento de estratégias e práticas para a construção de uma escola inclusiva que atenda a todos, por meio da utilização das TDIC como auxílio para potencialização e promoção da aprendizagem de todos os estudantes, independentemente de suas diferenças e singularidades.

\section{CONCLUSÃO}

Os atendimentos têm proporcionado melhoras na vida dos EPAEE, desenvolvendo a sua autonomia e aprendizagem para a inclusão social, escolar e digital.

Ainda, temos investido nos avanços obtidos na busca de uma escola ainda mais inclusiva e de qualidade para todos, promovendo a inclusão dos EPAEE na sociedade, na escola e no mundo de trabalho. 


\section{REFERÊNCIAS}

BRASIL. Ministério da Educação. Lei n. 9.394, de 20 de dezembro de 1996. Estabelece as diretrizes e bases da educação nacional. Diário Oficial da União, Brasília, DF, Seção 1, n. 248, p. 207, 23 dez. 1996.

BRASIL. MINISTÉRIO DA EDUCAÇÃO. SECRETARIA DE EDUCAÇÃO ESPECIAL. Política Nacional de Educação Especial na Perspectiva da Educação Inclusiva. Documento elaborado pelo Grupo de Trabalho nomeado pela Portaria Ministerial no 555/2007, prorrogada pela Portaria no 948/2007, de 07 de janeiro de 2008. Brasília, DF. MEC/SEESP,2008.

BRASIL. Ministério da Educação. Secretaria de Educação Especial. Política Nacional de Educação Especial. Brasília: MEC/SEESP, 1994

BRASIL. Ministério da Educação. Secretaria de Educação Especial. Política Nacional de Educação Especial. Brasília: MEC/SEESP, 1994 CAT, 2007. Ata da Reunião VII, de dezembro de 2007, Comitê de Ajudas Técnicas, Secretaria Especial dos Direitos Humanos da Presidência da República (CORDE/SEDH/PR). Disponível em:

<http://www.mj.gov.br/sedh/ct/corde/dpdh/corde/Comitê\%20de\%20Ajudas\%20Técnicas/Ata_VII_Re união_do_Comite_de_Ajudas_Técnicas.doc > Acesso em: 26 jun. 2014.

MANTOAN, M. T. E. Ser ou estar, eis a questão: Explicando o déficit intelectual. Rio de Janeiro: WVA, $1997 a$.

MANZINI, E. J. 2005. Tecnologia assistiva para educação: recursos pedagógicos adaptados. In: Ensaios pedagógicos: construindo escolas inclusivas. Brasília: SEESP/MEC, p.82-86.

SCHLÜNZEN, E. T. M. Mudanças nas Práticas Pedagógicas do Professor: criando um ambiente construcionista contextualizado e significativo para crianças com necessidades especiais físicas. São Paulo, 2000. Tese (Doutorado em Educação: Currículo). Pontifícia Universidade Católica de São Paulo (PUC_SP). 